\title{
Quando dois acervos se completam: a biblioteca de Mário de Andrade no Brasil e a Staatsbibliothek de Berlim
}

\author{
Rosângela Asche de Paula*
}

"Onde se queimam livros, no final se queimarão pessoas" Heinrich Heine

Desde 1999, sob coordenação da Profa. Dra. Telê Ancona Lopez, trabalho no "Projeto Integrado de Pesquisa: Biblioteca de Escritores e a Criação Literária”2. Nele, com bolsa da FAPESP, desenvolvo meu próprio projeto para o doutoramento na FFLCH-USP, $O$ expressionismo na biblioteca de Mário de Andrade: da leitura à criação, o qual visa analisar a contribuição dessa vanguarda em quatro obras desse escritor, publicadas na década de 1920: Paulicéia desvairada, Clã do jabuti, Losango cáqui e A escrava que não é Isaura.

0 projeto inclui o levantamento dos livros e periódicos do e sobre o expressionismo alemão presentes na biblioteca do escritor modernista, bem como o registro e a classificação das notas autógrafas, por meio das quais Mário dialogou com ficcionistas, poetas e teóricos do expressionismo de língua alemã. Esta segunda parte do trabalho, já em fase de finalização, tem como resultado um cd-rom que mostra, em fac-símile perfeito, mediante "scanner", tanto as obras do expressionismo e as notas de leitura, como a transcrição diplomática dessas mesmas notas (Notas MA). 0 cd-rom conta também com as Notas da pesquisa, que exploram o diálogo de Mário de Andrade com o expressionismo, diálogo que surgiu no espaço da leitura, gerando reflexão, comentário e, conseqüentemente, a criação.

As notas apontam a mescla das idéias e imagens expressionistas com as reflexões do modernista brasileiro sobre a arte e a cultura em seu país, detectadas no "Prefácio interessantíssimo" de Paulicéia desvairada e na poética d'A escrava que não é Isaura. Acompanham também a transfiguração de soluções estruturais e estilísticas de poetas e

* Doutoranda em Literatura Brasileira (FFLCH-USP), bolsista Fapesp e DAAD (junho-setembro 2004)

1 "Hassan: (...) Dort wo man Bücher verbrennt, verbrennt man auch am Ende Menschen”. Fala da personagem Hassan, da tragédia Almansor (1821).

20 projeto desenvolve-se no âmbito do IEB e da FFLCH-USP. 
prosadores do expressionismo nos textos de criação do poeta de Paulicéia desvairada, Losango cáqui e Clã do jabuti.

Concluída a segunda parte do projeto, sem a qual não poderei escrever a tese (ensaio), na qual trabalharei com obras e autores expressionistas como matrizes do pensamento e do texto poético de Mário de Andrade, percebi a necessidade de ampliar meus conhecimentos sobre a estética de Der Sturm: obter mais informações sobre livros e revistas, atualizar bibliografia sobre os autores, visitar museus, exposições e bibliotecas, deslocando-me para centros que, na Alemanha, são depositários de expressiva documentação sobre o assunto. Candidatei-me, portanto, a uma bolsa DAAD/ FAPESP que me garantiu a permanência de três meses na Alemanha, pelo Lateinamerika-Institut (LAI), da Freie Universität-Berlin, sob orientação da Profa ${ }^{a}{ }^{a}{ }^{a}$ Lígia Chiappini, entre junho e setembro de 2004, quando pesquisei em bibliotecas de Berlim e visitei museus em Munique.

Foi de extrema importância para minha pesquisa a consulta a bibliotecas em Berlim: supriu lacunas decorrentes do difícil acesso a uma bibliografia especializada no Brasil e da ausência, aqui, de obras que ofereçam uma dimensão histórica mais completa do significado da literatura e da arte expressionistas. Isto é, que focalizem esta vanguarda, no contexto de quatro momentos distintos e conturbados da história alemã: a Primeira Guerra, a República de Weimar, a ascensão do nazismo em 1933 e os bombardeios aliados de 1945.

Em minha pesquisa recolhi 134 títulos, entre artigos, livros e periódicos, que considerei válidos para alcançar os objetivos traçados para a tese: datar as edições presentes na biblioteca pessoal de Mário de Andrade; coletar material para a elaboração das biografias de autores do expressionismo que farão parte do cd-rom e recolher textos críticos e teóricos sobre a estética expressionista, que serão utilizados para fundamentar a análise das relações entre as leituras feitas por Mário do expressionismo e sua transfiguração na criação literária.

Apontar indícios da leitura do expressionismo feita por Mário de Andrade, vinculados a um diálogo que deságua na criação poética ou teórico-estética está ligado, dentro da crítica genética, ao estudo das bibliotecas de escritores. Devo deixar claro que estamos falando de diálogo, ou seja, uma troca, uma discussão de idéias, de conceitos visando, neste caso, a solução de problemas até se chegar à vanguarda modernista brasileira.

A estética expressionista, enquanto "abandono da expressão do objetivo em favor da expressão subjetiva" ${ }^{3}$ foi 
fundamental para Mário repensar a sociedade brasileira dos primeiros decênios do século XX, a qual seguia o modelo da cultura francesa, nas recentes metrópoles, que ofuscava e negava qualquer manifestação da cultura popular.

De 25 de junho a 15 de setembro concentrei-me no acervo da Staastbibliothek - Berlin, em seus dois prédios: Haus Unter-den-Linden e Haus Potsdamer Strasse.

\section{0 fim da segunda Guerra e o desaparecimento de li- vros do expressionismo}

A consulta ao acervo da Staastbibliothek foi, em termos de experiência pessoal e de formação, senão a mais importante, a mais significativa, na medida em que me forneceu informações sobre a própria história da biblioteca.

0 acervo que deu origem à Staastbibliothek ocupava o interior do Castelo de Berlim (Berliner Schloss). Friedrich II, o Grande, verificando que o espaço destinado à biblioteca real se tornara insuficiente, ordena, no final do século XVIII, a construção de um prédio destinado a acolher os volumes da Biblioteca Real. Atualmente este prédio, reconstruído após a guerra, abriga a Faculdade de Direito da Humbold Universität.

Com o aumento do número de exemplares, foi necessária a construção de um novo prédio, na rua Unter den Linden. Foi neste edifício, construído entre 1903-14 com projeto do arquiteto Ernst von Ihne, que realizei parte de minha pesquisa. A edificação, em parte destruída pelos bombardeios aliados em 1945, passa, ainda hoje, por uma reconstrução. No hall há fotos que contam a história: 0 bombardeio, as paredes antigas, milhares de livros espalhados a céu aberto. Cabe lembrar que houve muito empenho da comunidade em salvar os catálogos da biblioteca, graças aos quais se pode recuperar a totalidade das obras no acervo, antes da guerra.

Eu calculara que encontraria dificuldades para consultar os livros do e sobre o expressionismo, porque tinha a imagem da queima de livros, em frente à Humbold Universität em 1933, promovida pelo partido de Hitler, o NSDAP, e por jovens estudantes nazistas. Para minha surpresa, ao tentar reservar determinados livros pelo catálogo digital da Staastbibliothek'Berlin, eles recebiam, no registro, muitas vezes a indicação Kriegsverlusst möglich (provavelmente perdido na Guerra), acompanhada da sugestão ao consulente para solicitar a obra na sala de livros raros. Após o pedido, dentro de dois ou três dias, eu recebia as respostas: "Aqui

3 ANDRADE, Mário de. Expressionismo. In: Diário Nacional, São Paulo, 30 set. 1927. Arquivo Mário de Andrade, IEB-USP. 
está seu livro, que bom que o 'encontramos' ou "Sinto muito, o livro não foi encontrado. Foi perdido na Guerra”.

Muitos destes livros foram ou queimados realmente em 1933, ou perdidos após os bombardeios a Berlim em 1945. Vale lembrar que livros considerados raros na época e até mesmo obras de arte importantes segundo a ótica nazista para o resgate e preservação da cultura alemã (edições do século XV etc), foram transferidos, no início da guerra para mosteiros, porões de castelos ou até mesmo minas de sal, na previsão de ataques aéreos ou ação de saqueadores.

Após a guerra, com a partilha da Alemanha, o espólio também foi repartido em setores. Os livros que couberam à Polônia, por exemplo, foram deslocados para Krakau.

Fracionadas as bibliotecas, resgatar a integridade desses acervos torna-se tarefa apenas possivel se os catálogos anteriores à guerra se encontrarem preservados. Mesmo assim trata-se de uma reconstituição hipotética.

Para minha pesquisa, esse dado reforça a importância da parcela do expressionismo na biblioteca de Mário de Andrade, no Instituto de Estudos Brasileiros, parcela a qual, já antes da minha viagem, eu considerava de grande valor. Agora, percebo que essas obras reunidas pelo autor de Paulicéia desvairada têm seu alcance e seu valor ampliado até a história recente da Alemanha.

Verdadeiras "baixas de guerra" são as perdas da biblioteca de Berlim. Não descobri, até o momento, quais títulos foram queimados durante a caça aos intelectuais em 1933 e quais se perderam em 1945, quais se deslocaram dentro da Alemanha ou entraram em acervos da URSS ou da Polônia. Todas eles trazem a indicação: "possivelmente perdido na guerra". Para nossa sorte, diversos títulos de revistas e livros nessa condição na Alemanha, estão perfeitamente conservados na biblioteca de Mário de Andrade, em São Paulo. Bons exemplos são Georg Trakl, Dichtungen, na primeira edição de 1919, Diensterweg, de Gottfried Benn, de 1918 e o Ecce homo, de Georg Grosz.

Paralelamente, na Staatsbiblithek - Berlin, em uma espécie de jogo de tentativa e erro, pude localizar livros marcados como "Kriegsverlusst", o que foi o caso de Der Malik (1919), de Else Lasker-Schüler, já conhecido por mim no acervo de Mário. Recebi o volume das mãos do bibliotecário com um sorriso e a frase: "que bom que você pediu esse livro".

\section{Preciosidades na biblioteca de Mário de Andrade}

Menschheitsdämmerung, que é uma das obras mais importantes do expressionismo, está na biblioteca de Mário de 
Andrade. Primeira coletânea da poesia expressionista, organizada por Kurt Pinthus em 1919 e publicada em 1920, fez parte do index nazista. 0 organizador, aliás, no prefácio à edição de 1959, ressalta o caráter de raridade da primeira edição: "Milhares de exemplares do livro foram destruídos, tanto pelos nazistas, como pelas bombas. Após a ressureição da Alemanha, e sobretudo depois do redescobrimento do expressionismo, foi pedido nas livrarias e respeitado mais do que antes de 1933. É praticamente uma raridade nos sebos e pode chegar a preços extraordinários em leilões."

Além da importâcia pelos fatos relatados acima, o exemplar de Menschheitsdämmerung, na biblioteca do nosso modernista, goza da dupla natureza de livro e de manuscritos, uma vez que o lápis de Mário de Andrade ali deixou as marcas do leitor/ criador em 107 dos 270 poemas. As notas marginais no volume revelam tanto a leitura aplicada do estudante de alemão que traduz para melhor compreender os textos, como o poeta que traduz e ali esboça seus próprios versos.

Para que se tenha uma idéia do diálogo da criação de Mário de Andrade com a "jovem poesia alemã", apresentamos, em fac-símile, a tradução por ele esboçada nas entrelinhas e nas margens do poema de Jakob van Hoddis, "Weltende" ("Fim do mundo"), p.3. Ao lado dela, no intuito de divulgar este belo poema do expressionismo alemão, acrescento a tentativa de traduzir, minha e de Telê Ancona Lopez, que incorporou, por certo, soluções aventadas pelo poeta de Paulicéia desvairada.

\section{Sobre Jakob van Hoddis}

Nascido Hans Davidson em 1887, em Berlim, van Hoddis era o filho mais velho de um médico judeu. Seguindo a profissão do pai, atuou na Primeira Guerra. 0 nome Jakob van Hoddis foi por ele cunhado em 1909, como um anagrama do próprio sobrenome. Publicado pela primeira vez na revista Der Demokrat, no mesmo ano da fundação do Neuer Klub (Novo Clube), 1911, "Weltende", é considerado como o ponto de partida dos poemas expressionistas que trazem uma visão apocalíptica do mundo. Em 1912 van Hoddis passou por uma crise nervosa, a primeira de várias que lhe causaram internações até 1942, quando, em 30 de abril, foi deportado para a Polônia. Morreu entre abril e maio do mesmo ano possivelmente no campo de concentração de Sobibor.

4 PINTHUS, Kurt. Nach 40 Jahren. In: Menschheitsdämmerung: ein Dokument des Expressionismus. 32. Aufl. (32aed.). Berlin, Rowohlt, 2003, p.8. 


\section{E N S C H H E I T S \\ D $\ddot{A} \quad M \quad M \quad E \quad R \quad U \quad N \quad G$}

Symphonie jüngster Dichtung

HERAUSGEGEBEN

vos

K URT PINTHUS

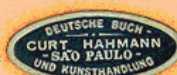

$3 \times{ }^{50}$

$\begin{array}{llll}1 & 9 & 2 & 0\end{array}$

ER NST ROWOHLT VERLAG BERLIN

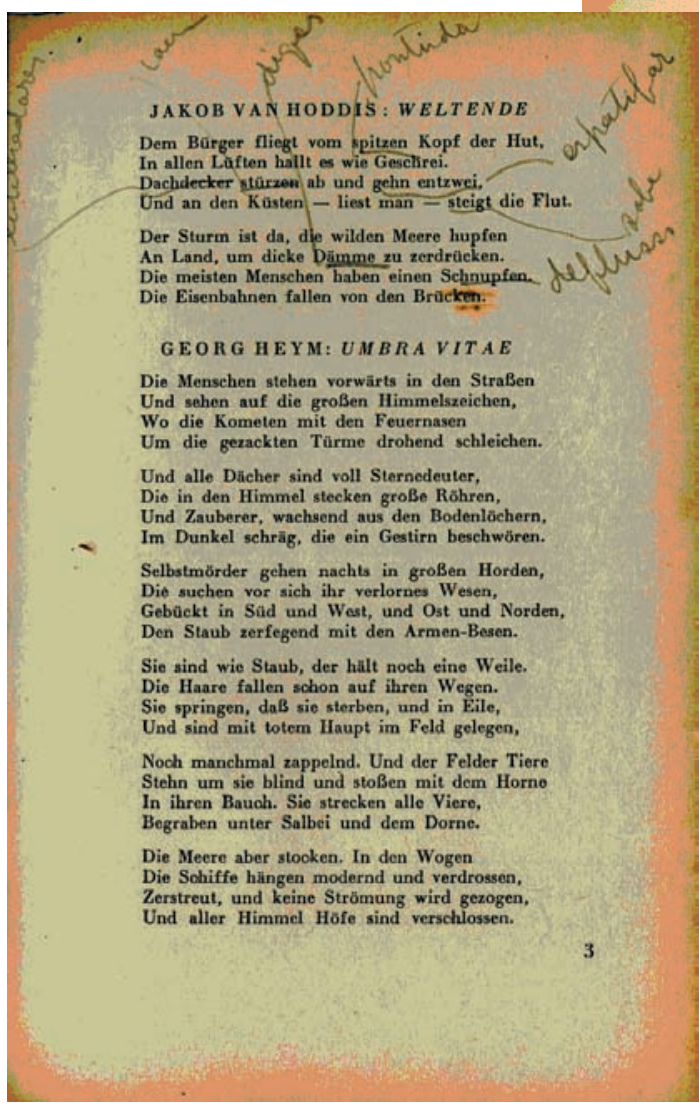

\section{MARIO DE ANDRADE}

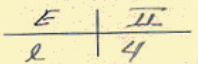

An Land, um dicke Dämme ru zerdrócken.

Die meisten Menschen haben einen Schnupfen.

Die Eisenbahnen fallen von den Brüket.

Wo die Komelen mit den Feuernasen

Und alle Dacher sind voll Sternedeuter,

Die in den Himmel stecken große Röhren,

Und Zauberer, wachsend aus den Bodenlōchern.

Noch manchmal zappelnd. Und der Felder Tiere

tehn um sie blind und stoßen mit dem Horne

In

Zerstreut, und keine Strömung wird gezogen,

Und aller Himmel Hôfe sind verschlossen. 


\section{Tradução}

"O fim do mundo"

O chapéu do burguês voa da cabeça estreita, Por toda parte ecoa a gritaria, Os que montam telhados despencam e se espatifam As marés explodem, contam os jornais.

A tempestade irrompe, os mares avultam selvagens Sobre a terra estourando os grandes diques. Os homens, a maioria funga e choraminga . Os trens precipitam-se das pontes.

Jakob van Hoddis

(Tradução de Mário de Andrade, Rosângela Asche de Paula e Telê Ancona Lopez)

Mário de Andrade dialoga com van Hoddis

Van Hoddis desnuda a figura do burguês, sempre objeto do sarcasmo expressionista. Cada verso preserva uma independência categórica. São "semelhantes a manchetes de jornal", como bem apontou Cláudia Cavalcanti ${ }^{5}$.

0 espaço do poema é a cidade. 0 tempo é o da angústia daqueles que vivenciam a atmosfera social e econômica do Império, que depois culminaria na Primeira Grande Guerra.

Neste poema, van Hoddis inaugura o uso da ordenação assindética das frases, o que causa um grande desconforto no leitor, segundo Cláudia Cavalcanti, uma vez que os elementos do grotesco e da ironia se vêem revestidos de métrica e rima precisas.

Poema anotado por Mário e lido provavelmente entre 1920-1921, "Weltende" mostra sobre o texto impresso apenas traduções de palavras. Porém, enquanto matriz, o poema ganha um alcance muito maior.

Transcrevo as anotações marginais de Mário:

Notas MA a lápis preto:

Verso 1: grifo em spitzen e tradução: "pontuda" Verso 3: grifo em Dachdecker e tradução: "entelhadores" Verso 3: grifo em stürzen e tradução: "caem"

Verso 3: grifo em gehn entzwei e tradução: "espatifar" Verso 4: grifo em steigt e tradução: "sobe" Verso 6: grifo em Dämme e tradução: "diques" Verso 7: grifo em Schnupfen e tradução: "deflusso"

5 CAVAlCANTI, Cláudia. Poesia expressionista alemã; uma antologia. São Paulo: Estação Liberdade, 2000, p.27. 
As notas marginais de Mário apontam elos entre o poema lido, a tradução visando uma compreensão e a conseqüente criação. Esta última, vai desembocar nos versos 1314 e 20-23 da "Ode ao burguês", em Paulicéia desvairada:

Eu insulto o burguês-funesto!

O indigesto feijão com toucinho, dono das tradições!

[...]

Morte à gordura!

Morte às adiposidades cerebrais!

Morte ao burguês-mensal!

Morte ao burguês-cinema! Ao burguês-tílburi!

Inserido no livro modernista de Mário de Andrade em 1922, esse poema exibe também elementos de renovação de linguagem, assim como a utilização do grotesco no ataque ao burguês e, de certa maneira, à arte que este representa. Ambos os poetas destinam o seu ódio ao burguês, movidos por questões da esfera política, social ou cultural.

Van Hoddis canta a destruição de tudo que se liga ao burguês através da visão apocalíptica do fim do mundo Weltende. A fantasia ultrapassa a revolta interna e faz com que o próprio mundo burguês destrua a figura em que se espelha.

0 poema de Mário, desde o título, "Ode ao burguês", que soa sarcástica e ambiguamente como "ódio ao burguês", em seu tom de pilhéria e ironia não poupa ataques, empregando sobretudo os pares de substantivos (marca do futurismo adotada pelos expressionistas) com função de adjetivar depreciativamente, reforçado pelo uso parcimonioso dos adjetivos. Em Paulicéia desvairada não é o mundo que destrói, mas sim a invectiva na linguagem que, ao longo do poema pinta o burguês como ser decadente e odiado por força de sua alienação:

Come! Come-ti a ti mesmo, oh! Gelatina pasma!

Oh! purée de batatas morais

Oh! cabelos nas ventas! oh! carecas! (v. 29-31)

\section{Conclusão}

Brasil e Alemanha se encontram, nesta pesquisa, não apenas no diálogo travado por Mário de Andrade com os expressionistas, como nas lacunas que são preenchidas à medida que se compara os dois acervos.

6 ANDRADE, Mário de. Paulicéia desvairada. São Paulo: Casa Mayença, 1922, p.67-9. 
O olhar sobre as obras do expressionismo literário alemão, em ambos, acusa proximidade e distanciamento, lacunas. Eles tocam quando, nos catálogos, há coincidência de títulos. Além disso, na biblioteca de Mário de Andrade, preservada em sua integridade material no Instituto de Estudos Brasileiros da Universidade de São Paulo (IEB-USP), contase também com a possibilidade de conhecer a localização dos volumes na casa da rua Lopes Chaves (cômodo, estante, prateleira e posição do volume na mesma). Assim acontece graças ao projeto coordenado por Antonio Candido que, na década de 1960, promoveu o tombamento da biblioteca e o registro da marginália, e ao fichário original por autores e obras. Por outro lado, na Staatsbiblítohek, o distanciamento se impõe, uma vez que apenas registros anteriores à Guerra proporcionam a "reconstrução" do acervo, em catálogos recuperados.

A destruição de bibliotecas, conforme Mathew Battles ${ }^{7}$, é um fenômeno que se intensificou no século XX, contrariando o movimento de criação das mesmas, no século XIX. E as guerras são as maiores causadoras dessas perdas. 0 que a História fixou quanto à expansão do III Reich repete-se agora na Bósnia e em Bagdá.

Eliminar o contingente intelectual e a produção cultural de um povo tem por trás a intenção de aniquilá-lo. A identidade de uma nação ou de uma população liga-se, de modo indissolúvel, ao conjunto das manifestações culturais. Não se joga uma bomba em uma biblioteca ou em um museu por engano. Como a própria história mostrou, são alvos importantes em uma guerra.

7 BATTLES, Mathew. A conturbada história das bibliotecas. Trad.: João Vergílio Gallermani Cuter. São Paulo: Planeta do Brasil, 2003, p. 157. 